\title{
Perencanaan Jaringan Drainase Sub Sistem Kalidami Surabaya
} \\ Jl. Arief Rahman Hakim, Surabaya 60111 \\ email: umboro@ce.its.ac.id, cia.hidroits@gmail.com
}

Risma Lupita Sari, Dr Techn Umboro Lasminto, ST., M.Sc dan Nastasia Festy Margini, ST., MT. Jurusan Teknik Sipil, Fakultas Teknik Sipil dan Perencanaan, Institut Teknologi Sepuluh Nopember

\begin{abstract}
Abstrak - Saluran Kalidami berada di kawasan Surabaya bagian timur. Saluran ini memiliki panjang 4270 meter dengan lebar bervariasi antara 11-33 meter. Saluran Kalidami membentang dari Kelurahan Airlangga, Gubeng dan berakhir di Selat Madura. Berdasarkan Peta Genangan Kota Surabaya Tahun 2013 terdapat beberapa daerah genangan di sekitar saluran Kalidami, diantaranya pada kawasan Kertajaya, Pucang anom, Dharmawangsa, Gubeng, Mojo, dan Airlangga. Genangan yang terjadi memiliki tinggi yang bervariasi antara 10-50 cm. Pada saluran primer kalidami terdapat buzem yang dilengkapi dengan pintu air dan rumah pompa untuk pengendalian banjir. Namun, saat pompa air dihidupkan pada saat hujan, daerah hilir saluran tidak mampu mengalirkan debit buangan pompa sehingga air pada saluran meluber.

Dalam Tugas Akhir ini dilakukan perencanaan drainase pada sub sistem Kalidami dengan meninjau kondisi saluran eksisting dan menggunakan program bantu HEC-HMS dalam analisa hidrologinya. Kemudian debit hasil dari HEC-HMS digunakan sebagai input debit banjir rencana pada analisa hidrolika. Dilakukan dua kali analisa hidrolika, yang pertama dengan kondisi eksising dan yang kedua dengan dengan saluran hasil rencana. Analisa hidrolika untuk saluran tersier menggunakan perhitungan analitik sedangkan untuk saluran sekunder dan primer menggunakan program bantu HEC-RAS.

Berdasarkan hasil analisa kondisi eksisting diperoleh bahwa genangan air yang terjadi pada DAS Kalidami terjadi karena kapasitas saluran yang tidak mampu mengalirkan debit banjir, baik akibat dimensi saluran yang kurang lebar, adanya sedimentasi maupun banyaknya sampah di saluran. Kapasitas saluran primer Kalidami saat ini tidak dapat mengalirkan debit banjir rencana, sehingga dibutuhkan perencanaan baru. Lebar saluran sekunder yang diperlukan berkisar antara 2 meter sampai 7 meter dengan kedalaman 2,5 meter. Sedangkan lebar saluran primer yang diperlukan adalah 12 meter pada bagian hulu kemudian melebar hingga 40 meter pada bagian hilir yang berbatasan dengan laut dengan kedalaman 2,5 meter. Kapasitas boezem dengan 5 buah pompa berkapasitas $1,5 \mathrm{~m}^{3} / \mathrm{dt}$ serta 2 buah pompa berkapasitas $3 \mathrm{~m}^{3} / \mathrm{dt}$ yang ada saat ini dapat berfungsi mengalirkan debit banjir rencana.
\end{abstract}

Kata kunci - Drainase, Genangan, HEC-HMS, HEC-RAS, Kalidami

\section{PENDAHULUAN}

P ERTUMBUHAN penduduk yang kian pesat menyebabkan kebutuhan akan hunian semakin meningkat. Banyak terjadi perubahan fungsi lahan resapan menjadi bangunan sehingga lahan resapan semakin berkurang. Akibatnya air limpasan hujan banyak yang mengalir di permukaan. Bila hal ini terus terjadi, maka saluran tidak akan mampu menampung air limpasan hujan yang terjadi. Akibatnya air akan meluap ke permukaan dan terjadi genangan.

Saluran Kalidami berada di kawasan Surabaya bagian timur. Saluran ini memiliki panjang 4270 meter dengan lebar antara 18-20 meter. Saluran Kalidami membentang dari Kelurahan Airlangga, Gubeng dan berakhir di laut di sisi timur Kelurahan Kejawen Wetan Putih Tambak.

Genangan air di Surabaya sering terjadi di berbagai daerah. Berdasarkan Peta Genangan Kota Surabaya Tahun $2013^{[1]}$ terdapat beberapa daerah genangan di sekitar saluran Kalidami, yakni Manyar Kertoarjo, Kertajaya Indah, Dharma Husada, Mojo Kidul, Gubeng, dan Pucang. Genangan yang terjadi memiliki tinggi yang bervariasi antara $10-50 \mathrm{~cm}$. Menurut (Jawa Pos, 20 Desember 2014) hujan yang terjadi pada tanggal 18 Desember 2014 lalu juga telah menyebabkan genangan di banyak daerah. Daerah yang terparah adalah Surabaya Timur, tepatnya kecamatan Gubeng. Selain itu genangan juga terjadi di wilayah Kelurahan Mojo, Dharmawangsa, Kertajaya, Kecamatan Sukolilo serta di beberapa daerah lainnya. Air yang menggenang di Keluruhan Mojo, tepatnya Mojo Kidul sampai setinggi $60 \mathrm{~cm}$. Selain karena hujan, genangan yang terjadi juga disebabkan oleh pasangnya air laut ${ }^{[2]}$.

Daerah-daerah genangan tersebut merupakan daerah padat penduduk. Sehingga bila dibiarkan genangan yang terjadi dapat menimbulkan masalah kesehatan serta mengganggu aktivitas penduduk sekitar. Oleh karena itu, perlu dilakukan perencanaan kembali sistem drainase di sub sistem Kalidami agar genangan yang terjadi dapat diatasi.

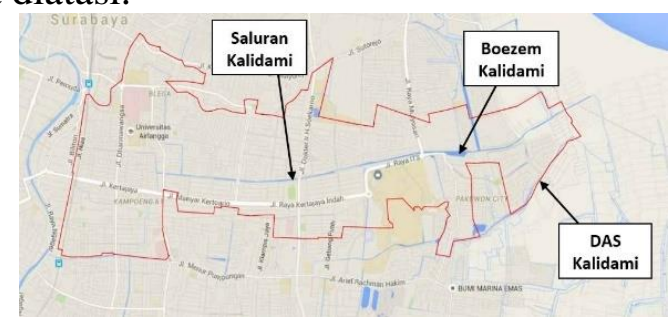

Gambar 1. Peta Lokasi 


\section{METODE PENELITIAN}

Metode yang digunakan dalam perencanaan ini adalah sebagai berikut :

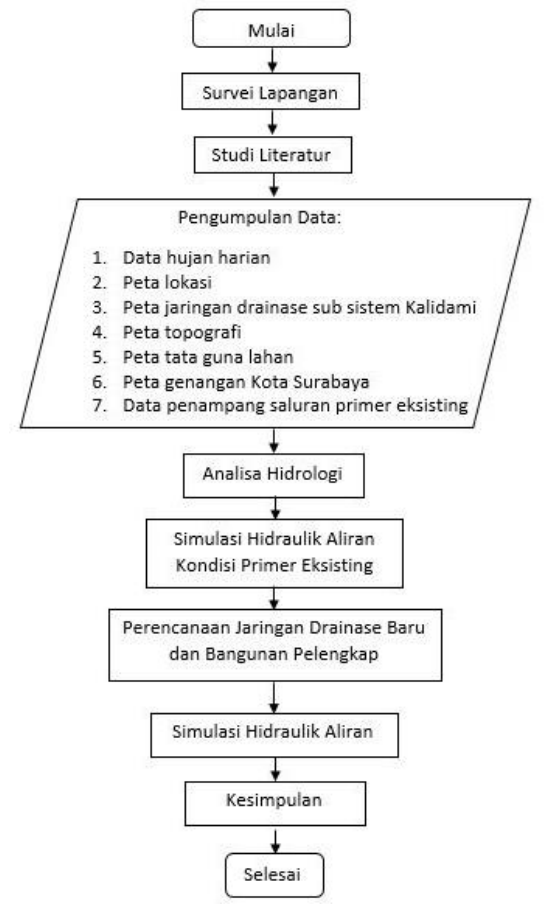

Gambar 2. Diagram Alir Metodologi Perencanaan

\section{HASIL DAN DISKUSI}

\section{A. Perhitungan Hujan Rencana}

Analisa hidrologi diperlukan untuk dapat mengetahui secara detail parameter-parameter hidrologi : karakteristik hujan, menganalisis hujan rancangan dan analisis debit rencana untuk dapat merancang saluran $\operatorname{air}^{[3]}$.

1. Perhitungan Curah Hujan Rata-Rata Maksimum

Perhitungan curah hujan menggunakan metode Poligon Thiessen. Terdapat 3 stasiun hujan yang berpengaruh terhadap kawasan DAS Kalidami, yakni stasiun hujan Wonokromo, Gubeng dan Keputih. Koefisien Thiessen dan Luas Daerah Pengaruh dapat dilihat pada Tabel 1. Kemudian dicari curah hujan rata-rata maksimum sebagai hasil distribusi hujan. Hasil dapat dilihat pada Tabel 2.

Tabel 1.

Luas Daerah Pengaruh dan Koefisien Thiessen Stasiun Hujan

\begin{tabular}{ccc}
\hline Stasiun Hujan & $\begin{array}{c}\text { Luas Pengaruh } \\
\text { Stasiun }\left(\mathbf{k m}^{\mathbf{2}}\right)\end{array}$ & $\begin{array}{c}\text { Koefisien Thiessen } \\
(\mathbf{W})\end{array}$ \\
\hline Wonokromo & 1,209 & 0,107 \\
Gubeng & 4,418 & 0,391 \\
Keputih & 5,658 & 0,501 \\
LUAS TOTAL & 11,284 & \\
\hline
\end{tabular}

Tabel 2.

Curah Hujan Rata - Rata Maksimum

\begin{tabular}{ccc}
\hline No & Tahun & Rmaks (mm) \\
\hline 1 & 2005 & 77,99 \\
2 & 2006 & 106,38 \\
3 & 2007 & 74,56 \\
4 & 2008 & 83,27 \\
5 & 2009 & 94,09 \\
6 & 2010 & 98,44 \\
7 & 2011 & 81,37 \\
8 & 2012 & 74,58 \\
9 & 2013 & 84,67 \\
10 & 2014 & 118,64 \\
\hline
\end{tabular}

2. Uji Parameter Statistik

Perhitungan parameter statistik untuk distribusi Normal, Gumbel Tipe I dan Pearson Tipe III dapat dilihat Tabel 3. Sedangkan parameter untuk Log Pearson Tipe III dan Log Normal dapat dilihat pada Tabel 4.

Tabel 3.

Perhitungan Parameter Statistik Untuk Distribusi Normal, Gumbel Tipe I dan Pearson Tipe III

\begin{tabular}{|c|c|c|c|c|c|c|}
\hline No & Tahun & $\begin{array}{c}\mathrm{R} \\
(\mathrm{mm})\end{array}$ & $\begin{array}{c}(\mathrm{R}-\overline{\mathrm{R}}) \\
(\mathrm{mm})\end{array}$ & $\begin{array}{c}(\mathrm{R}-\overline{\mathrm{R}})^{2} \\
\left(\mathrm{~mm}^{2}\right)\end{array}$ & $\begin{array}{c}(\mathrm{R}-\overline{\mathrm{R}})^{3} \\
\left(\mathrm{~mm}^{3}\right)\end{array}$ & $\begin{array}{c}(\mathrm{R}-\overline{\mathrm{R}})^{4} \\
\left(\mathrm{~mm}^{4}\right)\end{array}$ \\
\hline 1 & 2005 & 77,99 & $-11,41$ & 130,21 & $-1485,90$ & 16955,87 \\
\hline 2 & 2006 & 106,38 & 16,98 & 288,44 & 4898,61 & 83195,01 \\
\hline 3 & 2007 & 74,56 & $-14,84$ & 220,22 & $-3267,95$ & 48495,46 \\
\hline 4 & 2008 & 83,27 & $-6,13$ & 37,58 & $-230,34$ & 1411,96 \\
\hline 5 & 2009 & 94,09 & 4,69 & 22,01 & 103,25 & 484,36 \\
\hline 6 & 2010 & 98,44 & 9,04 & 81,68 & 738,21 & 6671,71 \\
\hline 7 & 2011 & 81,37 & $-8,03$ & 64,41 & $-516,91$ & 4148,49 \\
\hline 8 & 2012 & 74,58 & $-14,82$ & 219,62 & $-3254,73$ & 48233,92 \\
\hline 9 & 2013 & 84,67 & $-4,73$ & 22,39 & $-105,94$ & 501,26 \\
\hline 10 & 2014 & 118,64 & 29,25 & 855,28 & 25012,96 & 731509,59 \\
\hline & $\Sigma=$ & 893,98 & $\Sigma=$ & 1941,83 & 21891,25 & 941607,63 \\
\cline { 2 - 7 } & $\bar{R}=$ & 89,40 & \multicolumn{5}{l}{} \\
\cline { 2 - 6 } & \multicolumn{7}{c}{}
\end{tabular}

$S=\sqrt{\frac{1941,83}{10-1}}=14.689$

$\mathrm{CV}=\frac{14,689}{89,40}=0.164$

$\mathrm{CS}=\frac{10 \mathrm{x}-21891,25}{(10-1)(10-2) 14,689^{3}}=0.959$

$\mathrm{CK}=\frac{10^{2} \times 941607,63}{(10-1)(10-2)(10-3) 14,689^{4}}=4,013$

Tabel 4.

Perhitungan Parameter Statistik Untuk Distribusi Log Pearson Tipe III dan Log Normal

\begin{tabular}{|c|c|c|c|c|c|c|c|}
\hline No & Tahun & $\mathrm{R}(\mathrm{mm})$ & $\log R$ & $(\log R-\log R)$ & $(\log \mathrm{R}-\overline{\log R})^{2}$ & $(\log R-\overline{\log R})^{3}$ & $(\log \mathrm{R}-\overline{\log R})^{4}$ \\
\hline 1 & 2005 & 77,987 & 1,892 & $-0,054$ & 0,003 & $-0,00016$ & 0,0000087 \\
\hline 2 & 2006 & 106,381 & 2,027 & 0,081 & 0,006 & 0,00052 & 0,0000420 \\
\hline 3 & 2007 & 74,558 & 1,872 & $-0,074$ & 0,005 & $-0,00040$ & 0,0000298 \\
\hline 4 & 2008 & 83,268 & 1,920 & $-0,026$ & 0,001 & $-0,00002$ & 0,0000004 \\
\hline 5 & 2009 & 94,089 & 1,974 & 0,027 & 0,001 & 0,00002 & 0,0000005 \\
\hline 6 & 2010 & 98,436 & 1,993 & 0,047 & 0,002 & 0,00010 & 0,0000048 \\
\hline 7 & 2011 & 81,372 & 1,910 & $-0,036$ & 0,001 & $-0,00005$ & 0,0000017 \\
\hline 8 & 2012 & 74,578 & 1,873 & $-0,074$ & 0,005 & $-0,00040$ & 0,0000296 \\
\hline 9 & 2013 & 84,666 & 1,928 & $-0,019$ & 0,000 & $-0,00001$ & 0,0000001 \\
\hline 10 & 2014 & 118,643 & 2,074 & 0,128 & 0,016 & 0,00209 & 0,0002675 \\
\hline & & $\Sigma=$ & 19,464 & $\Sigma=$ & 0,042 & 0,00170 & 0,0003851 \\
\hline
\end{tabular}




$$
\begin{aligned}
& \mathrm{S}=\sqrt{\frac{0,042}{10-1}}=0.068 \\
& \mathrm{CV}=\frac{0.068}{1.946}=0,035 \\
& \mathrm{CS}=\frac{10 \mathrm{x}-0,0017}{(10-1)(10-2) 0.068^{3}}=0.743 \\
& \mathrm{CK}=\frac{10^{2} \times 0,000385}{(10-1)(10-2)(10-3)-0,068^{4}}=3,523
\end{aligned}
$$

Kemudian dipilih jenis distribusi yang parameternya memenuhi syata. Pemilihan jenis distribusi yang sesuai dapat dilihat pada Tabel 5.

Tabel 5.

Pemilihan Jenis Distribusi yang Sesuai

\begin{tabular}{|l|c|c|c|c|c|}
\hline \multirow{2}{*}{$\begin{array}{c}\text { Metode } \\
\text { Distribusi }\end{array}$} & \multicolumn{2}{|c|}{ Sifat Distribusi } & \multicolumn{2}{c|}{ Perhitungan } & \multirow{2}{*}{ Ket } \\
\cline { 2 - 5 } & $\mathrm{Cs}$ & $\mathrm{Ck}$ & $\mathrm{Cs}$ & $\mathrm{Ck}$ & \\
\hline Normal & 0 & 3 & 0,959 & 4,013 & NOT OK \\
\hline Gumbel & $\leq 1,139$ & $\leq 5,402$ & 0,959 & 4,013 & OK \\
\hline Pearson Type III & Fleksibel & Fleksibel & 0,959 & 4,013 & OK \\
\hline $\begin{array}{l}\text { Log Pearson } \\
\text { Type III }\end{array}$ & \multicolumn{2}{|c|}{$0<\mathrm{Cs}<9$} & 0,743 & 3,523 & OK \\
\hline Log Normal & \multicolumn{2}{|c|}{$\mathrm{Cs} \neq 0$} & 0,743 & 3,523 & NOT OK \\
\cline { 2 - 3 } & $\mathrm{Cs}=3 \mathrm{Cv}+\mathrm{Cv}^{2}=0,133$ & & \\
\hline
\end{tabular}

Berdasarkan Tabel 5, dapat diketahui bahwa terdapat 3 jenis distribusi yang dapat digunakan, yakni Distribusi Gumbel Tipe I, Pearson Tipe III dan Log Pearson Tipe III. Dari ketiga jenis distribusi tersebut dilakukan uji kecocokan yaitu uji Chi Kuadrat dan uji Smirnov - Kolmogorov untuk menentukan distribusi mana yang paling sesuai untuk digunakan ${ }^{[3]}$. Hasil uji Chi Kuadrat dan uji Smirnov - Kolmogorov dapat dilihat padaTtabel 6.

Tabel 6.

Hasil Uji Kecocokan

\begin{tabular}{|l|ccc|c|c|c|c|c|}
\hline \multirow{2}{*}{$\begin{array}{l}\text { Persamaan } \\
\text { Distribusi }\end{array}$} & \multicolumn{9}{|c}{ Chi-Square } & \multicolumn{4}{c|}{ Uji Kecocokan } \\
\cline { 2 - 9 } & $\mathrm{Xh}^{2}$ & Nilai & $\mathrm{X}^{2}$ & Evaluasi & Dmaks & Nilai & Do & Evaluasi \\
\hline Gumbel & 3,00 & $<$ & 5,991 & OK & 0,171 & $<$ & 0,41 & OK \\
\hline $\begin{array}{l}\text { Pearson } \\
\text { Type III }\end{array}$ & 1,00 & $<$ & 5,991 & OK & 0,171 & 0,41 & OK \\
\hline $\begin{array}{l}\text { Log Pearson } \\
\text { Type III }\end{array}$ & 1,00 & $<$ & 5,991 & OK & 0,152 & $<$ & 0,41 & OK \\
\hline
\end{tabular}

Berdasarkan Tabel 6, diketahui bahwa ketiga distribusi telah memenuhi syarat uji kecocokan distribusi. Sehingga, perhitungan curah hujan rencana dapat menggunakan metode distribusi Gumbel, Pearson Tipe III maupn Log Pearson Tipe III. Dalam tugas akhir ini perhitungan curah hujan rencana dilakuukan menggunakan distribusi Log Pearson Type III. Hasil perhitungan hujan rencana menggunakan metode Log Pearson Tipe III dapat

\begin{tabular}{|c|c|c|c|c|c|}
\hline \multirow{2}{*}{ Rt } & \multicolumn{2}{|c|}{ PUH } & \multirow{2}{*}{ Rt' } & \multicolumn{2}{|c|}{ PUH } \\
\hline & 2 & 5 & & 2 & 5 \\
\hline Jam & \multicolumn{2}{|c|}{$\mathbf{m m}$} & Jam & \multicolumn{2}{|c|}{$\mathbf{m m}$} \\
\hline 1 & 54,611 & 62,993 & 1 & 54,611 & 62,993 \\
\hline 2 & 34,403 & 39,683 & 2 & 14,195 & 16,373 \\
\hline 3 & 26,254 & 30,284 & 3 & 9,957 & 11,485 \\
\hline 4 & 21,672 & 24,999 & 4 & 7,927 & 9,143 \\
\hline
\end{tabular}
dilihat pada Tabel 7.
Tabel 7.

Tinggi Hujan pada jam ke-t

\section{Analisa Hidrologi}

Perhitungan debit banjir rencana dilakukan menggunakan program bantu HEC-HMS. Metode yang digunakan dalam tugas akhir ini adalah metode hidrograf satuan sintetik SCS (soil conversation service). Parameter yang dimasukkan meliputi : tinggi hujan, nilai impervious (daya kedap air), nilai curve number (daya serap air), nilai rata-rata kemiringan lahan, panjang antara titik terjauh cathment area terhadap saluran, time $\operatorname{lag}^{[4]}$. Output dari program HECHMS adalah debit banjir pada masing-masing saluran. Digunakan hujan periode ulang 2 tahunan untuk merencakaan saluran tersier dan hujan periode ulang 5 tahunan untuk saluran primer dan sekunder. Output HEC-HMS berupa debit puncak

\begin{tabular}{|c|c|c|c|c|c|}
\hline $\begin{array}{l}\text { Kode } \\
\text { Saluran }\end{array}$ & $\begin{array}{c}\text { Debit } \\
\text { Puncak } \\
\left(\mathrm{m}^{3} / \mathrm{s}\right)\end{array}$ & $\begin{array}{l}\text { Kode } \\
\text { Saluran }\end{array}$ & $\begin{array}{c}\text { Debit } \\
\text { Puncalk } \\
\left(\mathrm{m}^{3} / \mathrm{s}\right)\end{array}$ & $\begin{array}{l}\text { Kode } \\
\text { Saluran }\end{array}$ & $\begin{array}{c}\text { Debit } \\
\text { Puncak } \\
\left(\mathrm{m}^{3} / \mathrm{s}\right)\end{array}$ \\
\hline T1 & 0,3 & T27 & 0,8 & T53 & 0,6 \\
\hline T2 & 0,7 & T28 & 0,7 & T54 & 0,7 \\
\hline T3 & 0,3 & T29 & 0,7 & T55 & 1,9 \\
\hline $\mathrm{T4}$ & 0,3 & T30 & 0,5 & T56 & 0,6 \\
\hline T5 & 0,3 & T31 & 4,1 & T57 & 0,3 \\
\hline T6 & 0,3 & T32 & 0,5 & T58 & 0,3 \\
\hline $\mathrm{T7}$ & 0,2 & T33 & 1,0 & T59 & 0,7 \\
\hline T8 & 0,1 & T34 & 0,4 & T60 & 0,9 \\
\hline T9 & 0,2 & T35 & 0,6 & T61 & 0,6 \\
\hline T10 & 0,7 & T36 & 0,3 & T62 & 0,3 \\
\hline T11 & 0,8 & T37 & 0,8 & T63 & 1,6 \\
\hline T12 & 0,6 & T38 & 0,4 & T64 & 1,4 \\
\hline T13 & 0,4 & T39 & 0,4 & T65 & 3,3 \\
\hline T14 & 1,4 & T40 & 0,8 & T66 & 0,3 \\
\hline T15 & 0,5 & T41 & 1,5 & T67 & 0,6 \\
\hline T16 & 0,7 & T42 & 1,0 & T68 & 0,2 \\
\hline T17 & 0,9 & T43 & 0,6 & T69 & 2,3 \\
\hline T18 & 0,2 & T44 & 0,8 & T70 & 0,4 \\
\hline T19 & 1,5 & T45 & 0,2 & T71 & 0,3 \\
\hline T20 & 1,2 & T46 & 0,7 & T72 & 0,9 \\
\hline $\mathrm{T} 21$ & 1,0 & T47 & 0,6 & $\mathrm{~T} 73$ & 1,1 \\
\hline $\mathrm{T} 22$ & 1,0 & T48 & 0,6 & T74 & 0,5 \\
\hline T23 & 1,0 & T49 & 0,8 & T75 & 0,5 \\
\hline T24 & 0,5 & T50 & 1,3 & T76 & 1,9 \\
\hline $\mathrm{T} 25$ & 0,8 & T51 & 0,8 & T77 & 0,6 \\
\hline T26 & 1,5 & T52 & 0,5 & & \\
\hline
\end{tabular}
untuk saluran tersier dapat dilihat pada Tabel 8.

Tabel 8.

Debit Puncak DAS Kalidami 


\section{B. Analisa Hidrolika}

Analisa Hidrolika ialah analisa kapasitas penampang saluran terhadap debit banjir yang terjadi ${ }^{[3]}$. Dalam tugas akhir ini analisa hidrolika dilakukan dengan dua cara, yakni analisa kapasitas penampang saluran dengan perhitungan analitik untuk saluran tersier dan perhitungan menggunakan program bantu HEC-RAS untuk saluran sekunder dan primer.

\section{Analisa Kapasitas Saluran Tersier}

Penampang saluran tersier direncanakan menggunakan beton precast U-Ditch dengan dimensi yang bervariasi. Perhitungan dimensi saluran tersier dilakukan metode analitik dengan menggunakan rumus debit hidrolika ${ }^{[6]}$ :

$$
Q=\frac{1}{n} \times R^{\frac{2}{3}} \times I^{\frac{1}{2}} \times A
$$

Hasil perhitungan dimensi saluran tersier dapat dilihat pada Tabel 9.

Tabel 9.

Perencanaan Tipe $U$-Ditch Saluran Tersier

\begin{tabular}{|c|c|}
\hline $\begin{array}{c}\text { Kode } \\
\text { Saluran }\end{array}$ & $\begin{array}{c}\text { Tipe } \\
\text { U-Ditch }\end{array}$ \\
\hline T1 & Tipe 27 \\
\hline T2 & Tipe 38 \\
\hline T3 & Tipe 27 \\
\hline T4 & Tipe 27 \\
\hline T5 & Tipe 27 \\
\hline T6 & Tipe 27 \\
\hline T7 & Tipe 25 \\
\hline T8 & Tipe 22 \\
\hline T9 & Tipe 25 \\
\hline T10 & Tipe 38 \\
\hline T11 & Tipe 36 \\
\hline T12 & Tipe 34 \\
\hline T13 & Tipe 33 \\
\hline T14 & Tipe 43 \\
\hline T15 & Tipe 32 \\
\hline T16 & Tipe 38 \\
\hline T17 & Tipe 40 \\
\hline
\end{tabular}

\begin{tabular}{|c|c|}
\hline $\begin{array}{c}\text { Kode } \\
\text { Saluran }\end{array}$ & $\begin{array}{c}\text { Tipe } \\
\text { U-Ditch }\end{array}$ \\
\hline T18 & Tipe 25 \\
\hline T19 & Tipe 42 \\
\hline T20 & Tipe 43 \\
\hline T21 & Tipe 40 \\
\hline T22 & Tipe 40 \\
\hline T23 & Tipe 40 \\
\hline T24 & Tipe 32 \\
\hline T25 & Tipe 36 \\
\hline T26 & Tipe 42 \\
\hline T27 & Tipe 36 \\
\hline T28 & Tipe 38 \\
\hline T29 & Tipe 38 \\
\hline T30 & Tipe 32 \\
\hline T31 & Tipe 47 \\
\hline T32 & Tipe 32 \\
\hline T33 & Tipe 40 \\
\hline T34 & Tipe 33 \\
\hline
\end{tabular}

\begin{tabular}{|c|c|}
\hline $\begin{array}{c}\text { Kode } \\
\text { Saluran }\end{array}$ & $\begin{array}{c}\text { Tipe } \\
\text { U-Ditch }\end{array}$ \\
\hline T35 & Tipe 34 \\
\hline T36 & Tipe 27 \\
\hline T37 & Tipe 36 \\
\hline T38 & Tipe 33 \\
\hline T39 & Tipe 33 \\
\hline T40 & Tipe 36 \\
\hline T41 & Tipe 42 \\
\hline T42 & Tipe 40 \\
\hline T43 & Tipe 34 \\
\hline T44 & Tipe 36 \\
\hline T45 & Tipe 25 \\
\hline T46 & Tipe 38 \\
\hline T47 & Tipe 34 \\
\hline T48 & Tipe 34 \\
\hline T49 & Tipe 36 \\
\hline T50 & Tipe 43 \\
\hline
\end{tabular}

\section{Analisa Kapasitas Saluran Primer Eksisting}

Perencanaan dimensi saluran primer eksisting dilakukan dengan menggunakan program bantu HEC-RAS. HEC-RAS melakukan analisis hidrolika menggunakan asumsi aliran steady dan unsteady dan akan memberikan desain berdasarkan hasil analisis tersebut ${ }^{[7]}$. Dalam tugas akhir ini digunakan aliran unsteady. Debit banjir rencana yang dimasukkan pada unsteady flow data merupakan debit banjir hasil dari program HECRAS untuk hujan periode ulang 5 tahunan.

Posisi outlet saluran Kalidami yang berbatasan dengan laut mengakibatkan pasang surut air laut berpengaruh terhadap tinggi muka air di hilir saluran. Pada DAS Kalidami telah terdapat boezem dan rumah pompa. Pada boezem ini terdapat pintu dan pompa yang nantinya akan menahan backwater dan memompa air sehingga tidak terjadi luapan. Lokasi boezem dapat dilihat pada gambar 3.

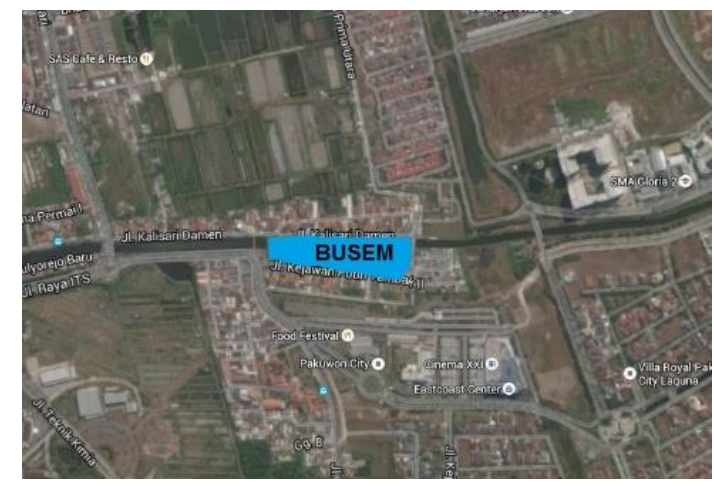

Gambar 3. Lokasi Boezem Kalidami

Boezem Kalidami memiliki luas kurang lebih $25000 \mathrm{~m}^{2}$ dengan kedalaman 2,5 m. Pada boezem terdapat rumah pompa yang memiliki 7 buah pompa banjir dengan 5 pompa kapasitas masingmasing $1,5 \mathrm{~m}^{3} /$ menit dan 2 pompa kapasitas masing-masing $3 \mathrm{~m}^{3} / \mathrm{dt}$. Outlet pompa ini berada pada hilir pintu air. Selain itu, pada daerah hulu primer juga terdapat rumah pompa Kalidami dengan 5 buah pintu air. Inlet dan outlet pompa ini terletak pada saluran primer Kalidami. Dalam rumah pompa ini terdapat 5 buah pompa dengan kapasitas $1,3 \mathrm{~m}^{3} / \mathrm{dt}$ setiap pompa nya. Pada tugas akhir ini analisa boezem dan pompa dilakukan dengan program bantu HEC-RAS.

Pada boezem Kalidami terdapat 4 pintu air dengan lebar masing-masing $3 \mathrm{~m}$ dan tinggi 3,7 m. Dalam tugas akhir ini analisa pintu air juga dilakukan menggunakan program bantu HECRAS. Dilakukan analisa pintu air pada kondisi kritis, yakni pada saat pasang surut air laut terjadi bersamaan dengan jam puncak banjir. Hasil HECRAS untuk saluran primer eksisting dapat dilihat pada Gambar 3 dan Gambar 4. 


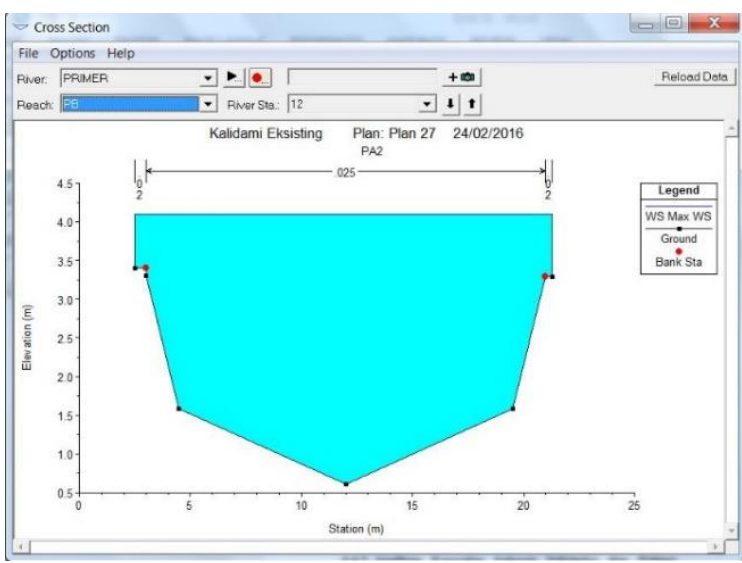

Gambar 3. Potongan Melintang Saluran Primer Eksisting Kalidami

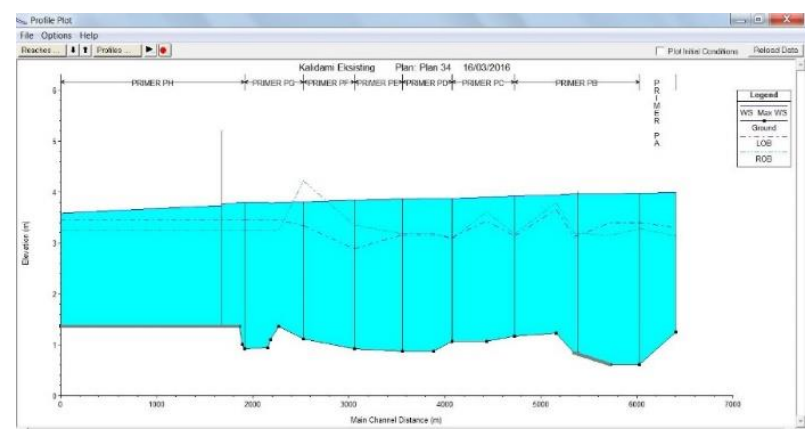

Gambar 4. Potongan Memanjang Saluran Primer Ekksisting Kalidami

Berdasarkan Gambar 3 dan Gambar 4 dapat dilihat bahwa saluran primer eksisting tidak dapat menampung debit banjir rencana sehingga dibutuhkan perencanaan baru.

3. Analisa Kapasitas Saluran Sekunder dan Primer Rencana

Perencanaan dimensi saluran sekunder dan primer rencana juga dilakukan menggunakan program bantu HEC-RAS. Debit banjir rencana yang dimasukkan pada unsteady flow data merupakan debit banjir hasil dari program HECRAS untuk hujan periode ulang 5 tahunan. Pada perencanaan ini dilakukan trial and error ${ }^{[8]}$ dengan mengubah dimensi penampang saluran hingga mendapatkan dimensi penampang yang optimal. Hasil HEC-RAS untuk saluran sekunder dan primer rencana dapat dilihat pada Gambar 5 dan 6.

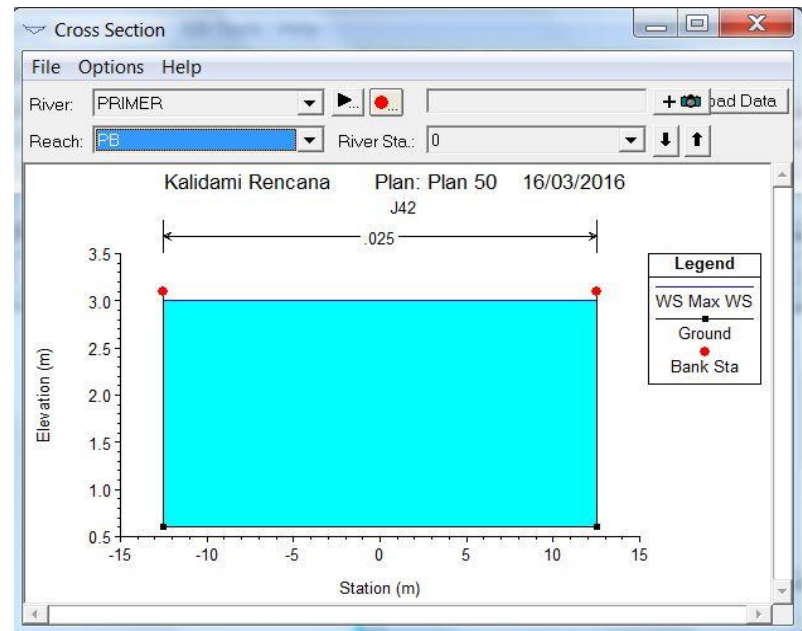

Gambar 5. Potongan Melintang Saluran Primer Kalidami

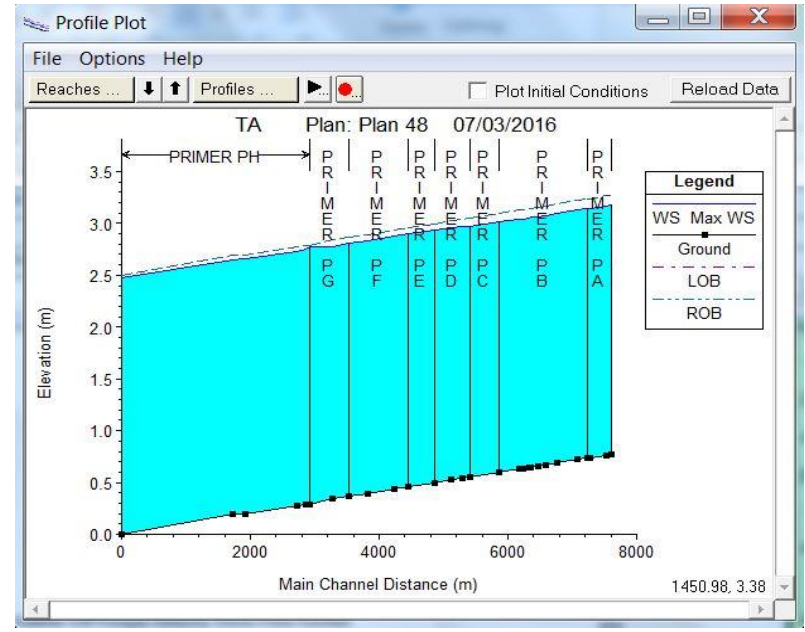

Gambar 6. Potongan Memanjang Saluran Primer Kalidami

Berdasarkan Gambar 5 dan 6 dapat dilihat bahwa saluran rencana dapat menampung debit banjir rencana. Dimensi penampang saluran dapat dilihat pada Tabel 10 dan 11 . 
Tabel 10.

Dimensi Saluran Sekunder Rencana

\begin{tabular}{|c|c|c|c|c|}
\hline $\begin{array}{l}\text { Kodo } \\
\text { Salurm }\end{array}$ & $\begin{array}{l}\text { Pryimg } \\
\text { Sshran (m) }\end{array}$ & $\begin{array}{l}\text { Labur } \\
\text { Sziran (m) }\end{array}$ & $\begin{array}{c}\text { Timggi } \\
\text { Shuran }(m)\end{array}$ & $\begin{array}{l}\text { Bectedk } \\
\text { Saluran }\end{array}$ \\
\hline \$1 & 200.08 & 7 & 25 & Shece:Pilo \\
\hline \$2 & 158.28 & 7 & 25 & Sheor Pile \\
\hline$\$ 3$ & 367.42 & 7 & 2.5 & Sheor:Pile \\
\hline 84 & 126.82 & $?$ & 25 & Sheorpilo \\
\hline S5 & 227.41 & 7 & 25 & Sheo: Pilo \\
\hline 86 & 273.71 & 7 & 2.5 & Shec: Pile \\
\hline हा & 207.68 & $?$ & 2.5 & Shece: Pile \\
\hline$\$ 5$ & 57.31 & 7 & 25 & Sheor Pile \\
\hline 39 & 247.15 & 7 & 2.5 & Sheor Pile \\
\hline$\$ 10$ & 439.22 & 7 & 2.5 & Shece:Pile \\
\hline SII & 138.42 & $?$ & 25 & SheetPile \\
\hline$\$ 12$ & 240.22 & 7 & 25 & Sheor:Pile \\
\hline$\$ 13$ & 33.21 & 7 & 2.5 & Shece:Pile \\
\hline \$14 & 381.28 & 7 & 25 & Shece: Pile \\
\hline S15 & 47.40 & 7 & 25 & Sheoe? Pile \\
\hline$\$ 16$ & 435.82 & 7 & 25 & Sheor:Pile \\
\hline \$17 & 110.06 & 7 & 2.5 & Shece: Pile \\
\hline$\$ 18$ & 216.39 & 7 & 25 & SheotPile \\
\hline$\$ 19$ & 212.15 & 7 & 25 & Shee: Pilo \\
\hline$\$ 20$ & 157.01 & 6 & 2.5 & Shece:Pile \\
\hline S21 & 246.18 & 6 & 25 & Sheor Pilo \\
\hline 522 & 258.06 & 6 & 2.5 & Sheo:Pile \\
\hline$\$ 23$ & 403.01 & 6 & 25 & Sheo: Pile \\
\hline$\$ 24$ & 338.55 & 6 & 25 & Sheor:Pile \\
\hline$\$ 25$ & 499.02 & 6 & 25 & Sheotpile \\
\hline$\$ 26$ & 247.09 & 6 & 2.5 & Shee:Pilo \\
\hline \$27 & 313.82 & 6 & 25 & Shece Pile \\
\hline$\$ 28$ & 35.40 & 6 & 2.5 & Sheor Pile \\
\hline$\$ 29$ & 176.24 & 6 & 2.5 & Shece:Pile \\
\hline 530 & 244.40 & 6 & 25 & Sheon Pilo \\
\hline S3! & 33.35 & 7 & 25 & Shece Pile \\
\hline S32 & 236.98 & 7 & 2.5 & Shece:Pile \\
\hline$\$ 33$ & 70.29 & 6 & 25 & Shece: Pile \\
\hline 534 & 141.75 & 6 & 25 & Sheor:Pile \\
\hline$\$ 35$ & 245.95 & 3 & 25 & Sheor Pile \\
\hline 336 & 34.44 & 7 & 2.5 & Sheoe: Pile \\
\hline 337 & 24.89 & 7 & 25 & Sheot?pilo \\
\hline \$35 & 133.21 & 7 & 25 & Sheor Pilo \\
\hline S399 & 300.49 & 3 & 2.5 & Shece:Pile \\
\hline$\$ 40$ & 425.05 & 2 & 2.5 & Tipo 42 \\
\hline 341 & 441.79 & 2 & 25 & Tipe 42 \\
\hline 342 & 538.74 & 2 & 25 & Tipe 42 \\
\hline$\$ 45$ & 311.08 & 6 & 2.5 & Sheos:Pile \\
\hline \$44 & 350.66 & 2 & 25 & Tipe 42 \\
\hline$\$ 45$ & 95.72 & 6 & 2.5 & Shee:Pilo \\
\hline 34? & 429.64 & 2 & 25 & Tipe 42 \\
\hline 348 & 42.20 & 2 & 2.5 & Tipe 42 \\
\hline उ49 & 139.29 & 6 & 2.5 & Shece Pile \\
\hline
\end{tabular}

Tabel 11.

Dimensi Saluran Primer Rencana

\begin{tabular}{|c|c|c|c|c|}
\hline $\begin{array}{c}\text { Kode } \\
\text { Saluran }\end{array}$ & $\begin{array}{c}\text { Panjang } \\
\text { Saluran }(\mathrm{m})\end{array}$ & $\begin{array}{c}\text { Lebar } \\
\text { Saluran }(\mathrm{m})\end{array}$ & $\begin{array}{c}\text { Tinggi } \\
\text { Saluran }(\mathrm{m})\end{array}$ & $\begin{array}{c}\text { Jenis } \\
\text { Perkuatan }\end{array}$ \\
\hline P1 & 91.25 & 12 & 2.5 & Sheet Pile \\
\hline P2 & 258.82 & 13 & 2.5 & Sheet Pile \\
\hline P3 & 35.24 & 13 & 2.5 & Sheet Pile \\
\hline P25 & 142.56 & 16 & 2.5 & Sheet Pile \\
\hline P4 & 325.17 & 18 & 2.5 & Sheet Pile \\
\hline P5 & 179.49 & 18 & 2.5 & Sheet Pile \\
\hline P6 & 115.22 & 20 & 2.5 & Sheet Pile \\
\hline P7 & 108.24 & 20 & 2.5 & Sheet Pile \\
\hline P8 & 34.05 & 24 & 2.5 & Sheet Pile \\
\hline P9 & 93.05 & 24 & 2.5 & Sheet Pile \\
\hline P10 & 47.18 & 24 & 2.5 & Sheet Pile \\
\hline P11 & 314.90 & 25 & 2.5 & Sheet Pile \\
\hline P12 & 455.15 & 25 & 2.5 & Sheet Pile \\
\hline P13 & 112.80 & 25 & 2.5 & Sheet Pile \\
\hline P14 & 176.29 & 28 & 2.5 & Sheet Pile \\
\hline P15 & 259.87 & 30 & 2.5 & Sheet Pile \\
\hline P16 & 418.49 & 30 & 2.5 & Sheet Pile \\
\hline P17 & 211.34 & 31 & 2.5 & Sheet Pile \\
\hline P18 & 414.32 & 31 & 2.5 & Sheet Pile \\
\hline P19 & 282.50 & 31 & 2.5 & Sheet Pile \\
\hline P20 & 268.97 & 33 & 2.5 & Sheet Pile \\
\hline P21 & 475.30 & 33 & 2.5 & Sheet Pile \\
\hline P22 & 195.14 & 33 & 2.5 & Sheet Pile \\
\hline P23 & 807.42 & 33 & 2.5 & Sheet Pile \\
\hline P24 & 1918.12 & 40 & 2.5 & Sheet Pile \\
\hline P1is & & & & \\
\hline
\end{tabular}

4. Analisa Saluran Rencana Beserta Bangunan Pelengkap Analisa saluran rencana beserta bangunan pelengkap dilakukan dengan menggunakan program bantu HEC-RAS. Analisa saluran yang dilakukan sama dengan analisa kapasitas saluran sekunder dan primer rencana, namun ditambah dengan adanya boezem, pompa dan pintu air eksisting seperti pada analisa kapasitas saluran primer dan bangunan pelengkap eksisting. Analisa dilakukan dengan memaksimalkan boezem dan pompa eksisting terlebih dahulu tanpa adanya penambahan luas boezem atau penambahan jumlah pompa. Hasil analisa boezem, pompa dan pintu air dapat dilihat pada gambar 7 .

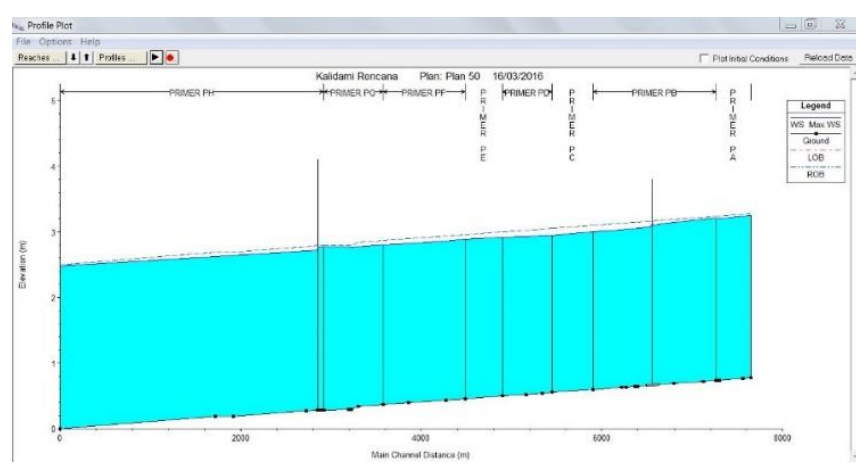

Gambar 7. Hasil Output Analisa Boezem, Pompa dan Pintu Air

Berdasarkan gambar 7, dapat dilihat bahwa kapasitas bangunan pelengkap boezem, pompa dan pintu air yang ada saat ini apabila dimodelkan 
dengan dimensi penampang rencana masih dapat menampung debit banjir rencana.

\section{KESIMPULAN}

1) Genangan air yang terjadi di beberapa tempat pada DAS Kalidami terjadi karena kapasitas saluran yang tidak mampu menampung debit banjir, baik akibat dimensi saluran yang kurang lebar, adanya sedimentasi maupun banyaknya sampah di saluran.

2) Berdasarkan hasil analisa hidrologi, didapatkan debit banjir rencana untuk saluran tersier sebesar 0,1 sampa $4,1 \mathrm{~m}^{3} / \mathrm{dt}$. Sedangkan untuk saluran primer mempunyai debit banjir rencana terbesar pada hilir sebesar $64,3 \mathrm{~m}^{3} / \mathrm{dt}$.

3) Berdasarkan hasil analisa hidrolika, diketahui bahwa kapasitas saluran primer Kalidami saat ini tidak mampu mengalirkan debit banjir rencana, sehingga diperlukan adanya perencanaan baru.

4) Saluran tersier dan beberapa saluran sekunder yang tidak terlalu lebar direncanakan menggunakan beton precast $\mathrm{U}$-ditch, sisanya direncanakan menggunakan saluran terbuka dengan perkuatan sheet pile pada sisi-sisi saluran. Lebar untuk saluran sekunder adalah 2 meter sampai 7 meter dengan kedalaman 2,5 meter. Lebar yang dibutuhkan untuk saluran primer adalah 12 meter pada bagian hulu saluran dan melebar hingga 40 meter pada bagian hilir saluran yang berbatasan dengan laut dengan kedalaman saluran 2,5 meter.

5) Berdasarkan hasil analisa, kapasitas busem dengan 5 buah pompa berkapasitas $1,5 \mathrm{~m}^{3} / \mathrm{dt}$ dan 2 buah pompa berkapasitas $3 \mathrm{~m}^{3} / \mathrm{dt}$ yang ada saat ini telah dapat menampung debit banjir rencana.

\section{DAFTAR PUSTAKA}

[1] Peta Genangan Kota Surabaya tahun 2013

[2] Gumilang, G. (2014, Desember 20). Hujan Deras dan Laut Pasang Rendam Surabaya. Jawa Pos, hal. -. Dipetik April 8, 2015, dari http://www.jawapos.com/baca/artikel/10516/Huj an-Deras-dan-Laut-Pasang-Rendam-Surabaya

[3] Soewarno. 1995. Hidrologi Aplikasi Metode Statistik untuk Analisa Data Jilid 1. Nova. Bandung.

[4] USACE. 2000. Hydrologic Modelling System HEC-HMS Technical Reference Manual. Juni 2015. http://www.hec.usace.army.mil
[5] Suripin. 2004. Sistem Drainase Perkotaan yang Berkelanjutan. Andi. Yogyakarta.

[6] Soemarto CD. 1986. Hidrologi Teknik. Surabaya : Usaha Nasional.

[7] USACE.2010. HEC-RAS Technical Reference Manual. USA : HEC-RAS

[8] Istiarto. 2014. Modul Pelatihan Pemakaian HEC$R A S$. Yogyakarta. 